\title{
Review
}

\section{Stroke Prevention: Extra-Cranial Carotid Artery Therapy}

\author{
Christopher J.White, MD; Jose David Tafur Soto, MD \\ Department of Cardiology, John Ochsner Heart \& Vascular Institute, Ochsner Medical Center, I 5 I 4 Jefferson Highway, New Orleans, LA 70 I 2 I, USA \\ "Corresponding author \\ Christopher J.White, MD \\ Professor and Chair Medicine and Cardiology, Department of Cardiology, John Ochsner Heart \& Vascular Institute, Ochsner Medical Center, 1514 Jefferson \\ Highway, New Orleans, LA 70I2I, USA;Tel. 504-842-3717; Fax. 504-842-4790; E-mail: cwhite@ochsner.org
}

Article information

Received: May 15 $5^{\text {th }}, 2019$; Revised: July 31 st 2019 ; Accepted: August Ist 2019 ; Published: August $7^{\text {th }}, 2019$

Cite this article

White CJ, Soto JDT. Stroke prevention: Extra-cranial carotid artery tsherapy. Neuro Open J. 2019; 6(I): 13-20. doi: 10.17| 40/NOJ-6-132

\section{ABSTRACT}

A patient-centered approach is reasonable in candidates for carotid revascularization. The patient and their physician should discuss the available treatment options, including revascularization (either carotid artery stenting (CAS) or carotid endarterectomy (CEA)) with their physician. There remains uncertainty regarding the value proposition for revascularization (either CEA or CAS) in asymptomatic patients as a strategy to prevent stroke. Investigation continues into characterizing high-risk carotid plaque subsets, but until that data is available, physicians and patients should continue to strive to achieve the best outcomes with the information that is currently available. The other consideration in asymptomatic patients is that there is a cumulative benefit to revascularization that is dependent on life expectancy. However, the magnitude of the benefit of revascularization, over the longer term in the setting of multifactorial medical therapy, including statins, is not known.

\section{Keywords}

Carotid endarterectomy; Carotid stent; Angioplasty; Embolic protection devices.

\section{INTRODUCTION}

$\mathrm{N}$ early 800,000 strokes occur each year in the United States, and over 120,000 Americans die annually from stroke. ${ }^{1}$ Atherosclerotic carotid artery disease is the leading cause of non-cardioembolic ischemic strokes. ${ }^{2}$ Carotid plaque most often causes cerebrovascular events due to plaque rupture with atheroembolization, rather than carotid artery occlusion $(<20 \%$ of ischemic strokes) with thrombosis. ${ }^{3}$

The risk of stroke related to carotid artery stenosis is strongly related to the presence or absence of preceding symptoms (transient ischemic attack (TIA), or stroke). Symptomatic patients have a much greater ( 5 to 10 -fold) risk of stroke when compared to asymptomatic patients, but the ratio asymptomatic to symptomatic patients undergoing carotid revascularization is $2.5: 1 .^{4}$ A TIA is an important warning sign associated with a $30 \%$ risk of stroke within 6-months.

\section{ANATOMIC IMAGING}

Digital subtraction angiography (DSA) is the gold standard for defining carotid anatomy with the North American Symptomatic Carotid Endarterectomy Trial (NASCET) method of stenosis measurement the most widely accepted methodology. However, invasive cerebral catheter-based angiography carries a risk of cerebral infarction of $0.5 \%$ to $1.2 \%$; therefore, non-invasive imaging should be the initial strategy for evaluation. Carotid doppler ultrasound (duplex) imaging, computed tomography angiography (CTA), and magnetic resonance angiography (MRA) are the non-invasive methods of stenosis assessment. Duplex imaging is the best initial choice given its safety profile, low-cost, and wide availability.

Carotid ultrasound has a high accuracy for carotid restenosis after endarterectomy. Criteria have been proposed to diagnose severe carotid stenosis. In most cases, $>80 \%$ stenosis correlates with systolic velocity $>300$ to $400 \mathrm{~cm} / \mathrm{s}$, diastolic velocity $>100$ to $135 \mathrm{~cm} / \mathrm{s}$ and ratio of internal carotid artery/common carotid artery (ICA/CCA) systolic velocity of $>3.5$. Other factors such as contralateral occlusion diminished cardiac output from severe left ventricular dysfunction, aortic stenosis, and common carotid artery stenosis may make these measurements less reliable.

\section{MEDICAL THERAPY}

Current anti-atherosclerotic medical therapy has advanced significantly since the 1990's early trials with the development of angiotensin converting enzyme-inhibitors (ACE-I), angiotensin receptor blockers (ARB), direct renin blockers, statin drugs and 
newer antiplatelet agents. Medical therapy for carotid atherosclerosis should focus on preventing stroke and stabilizing atherosclerotic lesions to prevent plaque rupture and atheroembolization. Blood pressure control is of paramount importance since it is a primary risk factor for stroke; it is also a risk factor for atrial fibrillation and myocardial infarction which both increase the likelihood of stroke. ${ }^{5}$ Smoking cessation and control of diabetes mellitus are also important factors in reducing cardiovascular events.

Cholesterol lowering with statin drugs in patients treated for cardiovascular disease prevention demonstrated a lower the risk of stroke. ${ }^{6,7}$ It is possible that statins prevent strokes through pleiotropic effects on endothelial function and plaque stabilization in addition to their lipid-lowering properties. Current American Heart Association/American Stroke Association (AHA/ASA) stroke guidelines endorse the American College of Cardiology (ACC)/AHA recommendations for the use of statins which recommend that high-intensity statin therapy be initiated or continued as first-line therapy in patients $\leq 75$-years of age that have clinical atherosclerotic cardiovascular disease unless contraindicated and it should be considered in those $>75$-years of age if the benefit outweighs the risk. ${ }^{8}$

The stroke prevention by aggressive reduction in cholesterol levels (SPARCL) trial demonstrated that high-dose atorvastatin is effective for secondary stroke prevention in patients with an ischemic stroke or TIA but no coronary heart disease. ${ }^{6}$ The justification for the use of statins in prevention: an intervention trial evaluating rosuvastatin (JUPITER) study showed that rosuvastatin treatment in patients with normal cholesterol levels but elevated levels of C-reactive protein is effective in reducing the rate of stroke?

The antithrombotic trialists' collaboration meta-analysis of high-risk patients, found that antiplatelet therapy reduced the occurrence of any vascular event by $25 \%$, non-fatal stroke by about $25 \%$, and death due to vascular cause by about $15 \% .{ }^{9}$ Aspirin was the most widely used drug with doses of $75-150 \mathrm{mg}$ as beneficial as higher doses. Among patients with symptomatic vascular disease, including stroke, the clopidogrel versus aspirin in patients at risk of ischemic events (CAPRIE) trial demonstrated that clopidogrel $75 \mathrm{mg}$ daily was associated with an $8.7 \%$ relative risk reduction in ischemic stroke, MI, or vascular death versus aspirin $325 \mathrm{mg}$ daily $(5.32 \%$ vs. $5.83 \% p=0.043) .{ }^{10}$ For the patients who presented with stroke, however, the benefit was not significant.

In the management of atherothrombosis with clopidogrel in high-risk patients (MATCH) trial, clopidogrel $75 \mathrm{mg}$ daily plus aspirin $75 \mathrm{mg}$ daily was compared to clopidogrel $75 \mathrm{mg}$ daily alone. ${ }^{11}$ Among stroke patients, the combination regimen did not improve vascular outcomes but significantly increased the number of major and life-threatening bleeding complications.

The clopidogrel for high atherothrombotic risk and ischemic stabilization, management, and avoidance (CHARISMA) trial included over 4,300 patients with a prior TIA or stroke and found that aspirin 75-162 $\mathrm{mg}$ daily was as effective as aspirin plus clopidogrel in preventing future MI, stroke, or cardiovascular death in patients with multiple risk factors or with clinically evident cardiovascular disease. ${ }^{12}$ This study also found that $81 \mathrm{mg}$ of aspirin is the optimal dose for safety and efficacy for prevention.

The AHA/ASA guidelines recommend that all patients with carotid atherosclerosis be placed on anti-platelet medications. Aspirin 81 or $100 \mathrm{mg}$ daily or clopidogrel $75 \mathrm{mg}$ daily alone in patients who cannot tolerate aspirin should be administered for secondary prevention of stroke. ${ }^{8}$

\section{SURGICAL THERAPY TO PREVENT STROKE}

\section{Asymptomatic Patients}

There have been three historical randomized studies comparing carotid endarterectomy (CEA) to antiplatelet (aspirin) therapy in the treatment of moderate $(\geq 50 \%-60 \%)$ carotid stenosis in patients without focal neurologic symptoms, that are all made less relevant by the effectiveness of modern anti-atherosclerotic therapy..

The veterans affairs cooperative study (VACS) randomized 444 men with asymptomatic carotid stenosis of $\geq 50 \%$ by angiography to medical therapy plus CEA or medical therapy alone. ${ }^{13}$ All patients were assigned aspirin $650 \mathrm{mg}$ twice daily though many did not tolerate that dose. The periprocedural 30-day risk of stroke or death in the CEA group was $4.7 \%$. At nearly 4 -years of follow-up, the ipsilateral neurologic event rate (including TIA, transient monocular blindness, and fatal and nonfatal stroke), was $8 \%$ in the surgical arm and $20.6 \%$ in the medical arm $(p<0.001)$. The risk of ipsilateral stroke alone was reduced from $9.4 \%$ with medical treatment to $4.7 \%(p<0.06)$ with CEA. Notably, there was no difference between surgery and medical therapy for combined stroke or death.

The asymptomatic carotid atherosclerosis study (ACAS) randomized 1,662 asymptomatic patients with carotid stenosis $\geq 60 \%$ to medical therapy or medical therapy with CEA. ${ }^{14}$ All patients received aspirin $325 \mathrm{mg}$ daily. Angiography was performed only in the CEA group and was associated with a $1.2 \%$ periprocedural risk of stroke. The 30-day risk of stroke or death in the surgical group, including the risk associated with angiography, was $2.7 \%$. The projected 5-year risk of ipsilateral stroke and any peri-operative stroke or death was reduced from $11 \%$ in the medical arm to $5.1 \%$ with CEA. The number of patients needed to treat (NNT) with surgery to prevent 1 ipsilateral stroke at 5-years was 19 . The benefit for women (17\% reduction in events) was less than for men $(66 \%$ reduction).

The asymptomatic carotid surgery trial (ACST) evaluated 3,120 asymptomatic patients with $\geq 60 \%$ carotid stenosis by ultrasound. Patients were randomized to CEA with medical management or medical management alone. Drug treatment was left to the discretion of the patients' primary physicians-this usually included antiplatelet medications, antihypertensive therapy, and, in the later years of the study, lipid-lowering agents. The 30day peri-operative risk of stroke or death was 3.1\%. The 5 -year risk of peri-operative death or total stroke was reduced from $11.8 \%$ to $6.4 \%$ with CEA and approximately half the strokes were disabling. 
The benefit of surgery was significant across all degrees of moderate to severe stenosis (60-90\% stenosis) however, CEA did not reduce overall stroke and death, and did not show any benefit in women or in patients older than 75 -years of age. ${ }^{15}$

Current data estimates the risk of progression of an asymptomatic carotid artery stenosis to occlusion with modern medical therapy to be $1 \%$ per year. In a cohort of 3,681 patients with yearly duplex follow-up, $316(8.6 \%)$ asymptomatic patients had occlusion that occurred during serial ultrasound observation. Of these, $80 \%$ (254) of the occlusions occurred before the initiation of modern intensive medical therapy. ${ }^{16}$

In asymptomatic patients, the AHA/ASA guidelines recommend it is reasonable to consider performing CEA in asymptomatic patients who have $>70 \%$ stenosis of the internal carotid artery if the risk of peri-operative stroke, MI, and death is low $(<3 \%)$ and life expectancy is at least 5 -years. ${ }^{8}$ The CREST-2 trial is currently enrolling asymptomatic patients and features 2 parallel arms (Figure 1) with one arm comparing CEA with best medical management versus best medical management alone.

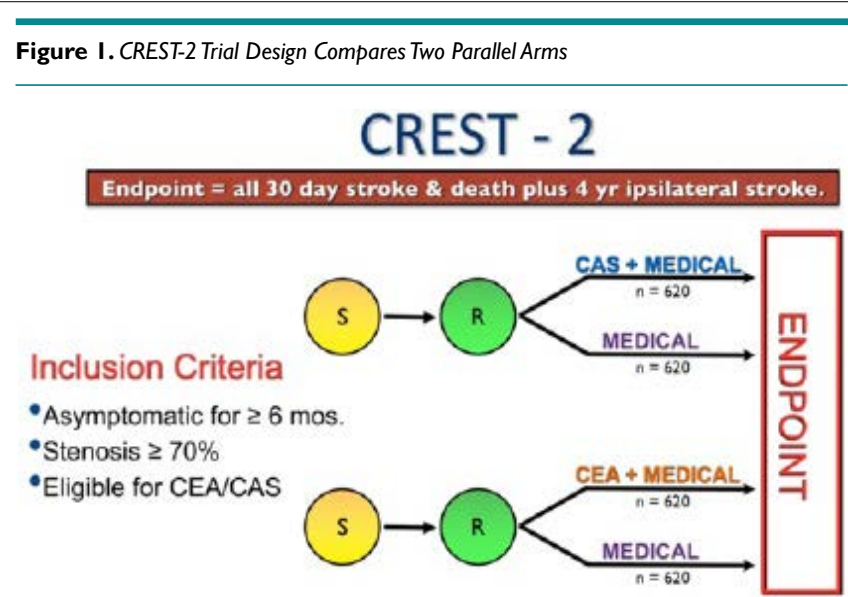

CEA with best medical therapy to medical therapy alone and CAS with best medical therapy to best medical therapy alone. The trial does not compare CEA to CAS as they were deemed equal alternatives during trial design.

\section{Symptomatic Patients}

Symptomatic carotid disease is defined as focal neurologic symptoms of sudden onset within 6-months and in the appropriate carotid artery. Prior to the development of modern anti-atherosclerotic therapy with antiplatelet, antihypertensive, and lipid-lowering therapy and diabetes control, the natural history of symptomatic carotid artery stenosis in the 1990's was reflected in the medical arm (aspirin, discussion of hypertension and diabetes control, and advice to stop smoking) of North American symptomatic carotid endarterectomy trial (NASCET). Overall, the 5-year risk of ipsilateral stroke in those medically managed was $22 \%$ depending on the severity of the stenosis. The NNT for symptomatic patients undergoing CEA to prevent 1 ipsilateral stroke at 5-years was 12. Females derived no significant benefit from CEA. In the medical treatment arm, the risk of any stroke at 5-years was $15 \%$ for women and $25 \%$ for men. ${ }^{17}$ The incidence of stroke increased with the severity of stenosis, and the 3 -year risk of ipsilateral stroke in symptomatic patients with stenosis greater than $80 \%$ was $26.5 \%$, however, as the stenosis approaches near occlusion (95\% to $99 \%$ ), the risk of ipsilateral stroke dropped down to $17.2 \%{ }^{18}$ Results were similar in the European carotid surgery trial (ECST). ${ }^{19}$

Current guidelines recommend CEA in symptomatic average surgical risk (ASR) patients if the stenosis is $>70 \%$ as documented by non-invasive imaging or $>50 \%$ as documented by catheter angiography and the anticipated rate of peri-operative stroke or mortality is less than $6 \% .^{20}$

\section{CAROTID ARTERY STENTING}

\section{High Surgical Risk (HSR) Patients}

When interpreting data on carotid stenting, it is important to realize that a patient who is at high-risk for surgery (HSR) is not necessarily at increased risk for stenting (and vice versa). The stenting and angioplasty with protection in patients at high-risk for endarterectomy (SAPPHIRE) trial is the only randomized trial comparing HSR patients treated with CEA or carotid artery stenting (CAS). ${ }^{21}$ Features that place a patient at increased risk for complications from CEA and CAS are summarized in Table 1. SAPPHIRE randomized 334 patients with a symptomatic stenosis of $\geq 50 \%$ or an asymptomatic stenosis $\geq 80 \%$ ( $~ 30 \%$ were symptomatic) to either CEA or CAS. The primary endpoint of death, stroke, or MI at 30-days plus ipsilateral stroke or death from neurological cause between day 31 and 1 -year occurred in $12.0 \%$ of patients in CAS versus $19.2 \%$ for CEA ( $p=0.004$ for non-inferiority) (Figure 2). The 30-day stroke and death rate among asymptomatic patients was $4.6 \%$ for the CAS group and 5.4\% for the CEA group. At 3-years, there were no differences between CEA or CAS.

\begin{tabular}{|c|c|c|c|}
\hline \multicolumn{2}{|c|}{ High Risk Features for CAS } & \multicolumn{2}{|c|}{ High Risk Features for CEA } \\
\hline $\begin{array}{l}\text { Clinical } \\
\text { Features }\end{array}$ & $\begin{array}{l}\text { Angiographic } \\
\text { Features }\end{array}$ & Comorbidities & Anatomic Features \\
\hline Age $\geq 75 / 80$ & $\begin{array}{l}\text { Severe Tandem } \\
\text { Lesions }\end{array}$ & Age $\geq 80$ & Lesion C2 or higher \\
\hline Renal failure & $\begin{array}{l}\geq 2 \text { acute }\left(90^{\circ}\right. \\
\text { bends) }\end{array}$ & $\begin{array}{l}\text { Class III/IV CHF } \\
\text { or angina }\end{array}$ & Lesion below clavicle \\
\hline $\begin{array}{l}\text { Multiple } \\
\text { lacunar Strokes }\end{array}$ & $\begin{array}{l}\text { Circumferential } \\
\text { calcification }\end{array}$ & $\begin{array}{l}L M / \geq 2 \text { Vessel } \\
C A D\end{array}$ & $\begin{array}{l}\text { Prior neck surgery } \\
\text { (including ipsilateral CEA) }\end{array}$ \\
\hline Dementia & $\begin{array}{l}\text { Evidence of } \\
\text { thrombus }\end{array}$ & LVEF $\leq 30 \%$ & $\begin{array}{l}\text { Contralateral carotid } \\
\text { occlusion }\end{array}$ \\
\hline \multirow[t]{3}{*}{$\begin{array}{l}\text { Bleeding } \\
\text { disorder }\end{array}$} & $\begin{array}{l}\text { Poor vascular } \\
\text { access }\end{array}$ & $\begin{array}{l}\text { Recent } \mathrm{MI}(>1 \\
\text { but }<30 \text { days) }\end{array}$ & $\begin{array}{l}\text { Contralateral laryngeal } \\
\text { nerve palsy }\end{array}$ \\
\hline & & $\begin{array}{l}\text { Severe chronic } \\
\text { lung disease }\end{array}$ & Neck Radiation \\
\hline & & Renal failure & Tracheostomy \\
\hline
\end{tabular}

The vast majority of contemporary CAS registry data focuses on HSR patients, and data from over 10,000 HSR patients have been published. These registries generally include symptomatic patients with $\geq 50 \%$ stenosis and asymptomatic patients with $\geq 70$ $80 \%$ stenosis. Data from many of these studies are summarized in Figure 3. In HSR patients who require revascularization for stroke 
prevention, CAS is the preferred strategy in patients who 1) can be treated by an experienced operator and 2) have suitable anatomy for CAS.

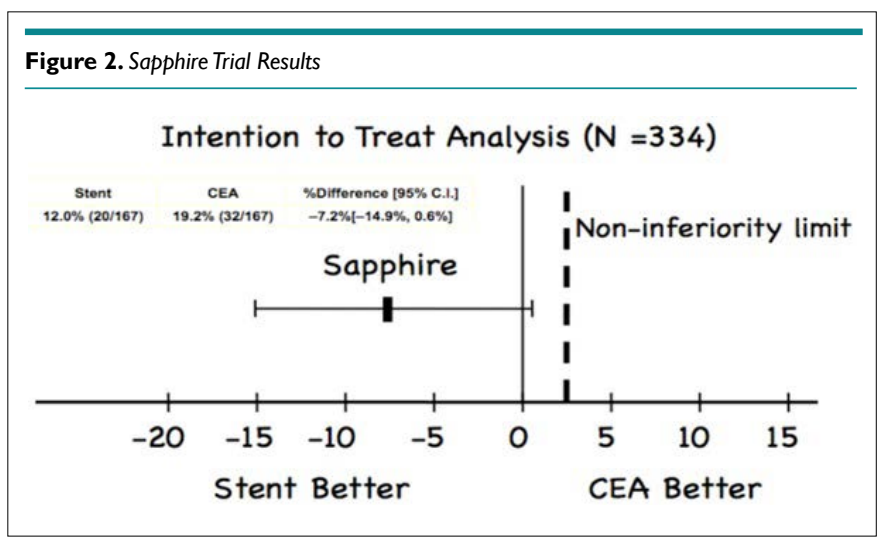

Figure 3. Registry Trials Comparing CAS to CEA in High Surgical Risk (HSR) Patients

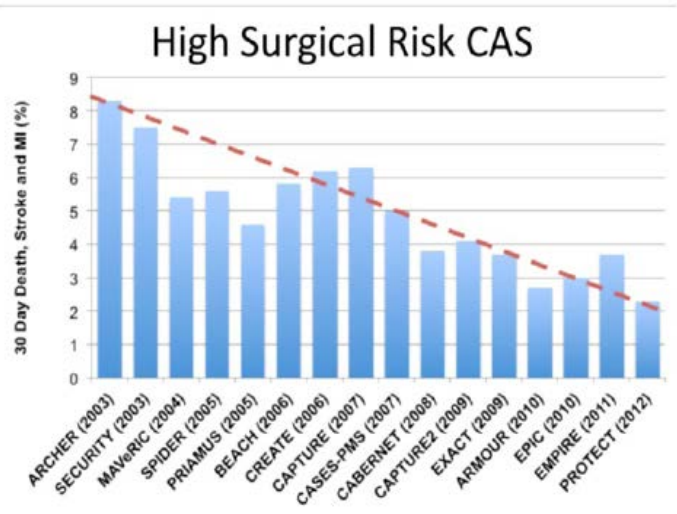

CAS in Symptomatic Patients

Four large randomized studies in ASR patients have compared CAS to CEA..$^{22-25}$ Three of these trials were conducted in Europe and their results were compromised by allowing inexperienced CAS operators to participate in the trials and not requiring the use of embolic protection devices (EPD's).

The endarterectomy versus angioplasty in patients with symptomatic severe carotid stenosis (EVA-3S) trial randomized only symptomatic ASR patients with carotid stenosis of $\geq 60 \%$ to either CEA or CAS. ${ }^{23}$ All patients had to be "suitable candidates" for both procedures and had ipsilateral neurological symptoms within 120-days of enrollment. The use of EPDs was "optional" and many of the investigators were "tutored" while treating patients. The 30-day incidence of stroke or death was $9.6 \%$ in the CAS group and $3.9 \%(p=0.004)$ in the CEA group.

The stent-supported percutaneous angioplasty of the carotid artery versus endarterectomy (SPACE) trial randomized 1,214 symptomatic, ASR patients to either CEA or CAS. ${ }^{22}$ The use of EPDs was optional and inexperienced operators were tutored during patient enrollment. The 30-day rate of ipsilateral stroke or death was not different between the two groups $(6.8 \%$ in the CAS group and $6.3 \%$ in the CEA group, $p=0.09$ for non-inferiority). However, the two-year outcomes for this trial demonstrated a statistically significant benefit for CAS over CEA in patients $<68$ years of age.

International carotid stenting study (ICSS) enrolled over 1,700 symptomatic ASR patients and randomized them to either CAS or CEA. ${ }^{24}$ Use of EPDs was optional. To qualify as an experienced center, a center had to have a surgeon who had performed 50 CEA procedures and an intervention a list who had performed 10 CAS procedures. If the center was less experienced, they were "tutored" while enrolling patients into the study. The number of fatal or disabling strokes and cumulative 5-year risk did not differ between the CAS and CEA groups (6.4\% vs 6.5\%; hazard ratio [HR] 1.06, 95\% CI 0.72-1.57, $p=0.77)$. The distribution of modified Rankin scale scores at 1-year, 5-years, or final follow-up did not differ between treatment groups. ${ }^{26}$

Carotid revascularization endarterectomy versus stenting trial (CREST) is the largest $(n=2,502)$ randomized trial published comparing CAS with EPD's to CEA in ASR patients and included both symptomatic $(\mathrm{n}=1,321)$ and asymptomatic $(n=1,181)$ patients. ${ }^{25}$ The primary outcome of peri-procedural stroke, death, or MI and follow-up ipsilateral stroke at 4-years in symptomatic patients was not significantly different between the two groups $(8.0 \%$ for CAS and $6.4 \%$ for CEA, $p=0.14)$. During the periprocedural period, rates of the primary end point did not differ significantly between the CAS group and the CEA group among 1,321 symptomatic patients (6.7\% vs. 5.4\%; hazard ratio for stenting, 1.26; $95 \% \mathrm{CI}, 0.81$ to 1.96$)$. The primary outcome of periprocedural stroke, death, or MI and follow-up ipsilateral stroke at 4-years in symptomatic patients was not significantly different between the two groups $(8.0 \%$ for CAS and $6.4 \%$ for CEA, $p=0.14)$.

In the overall trial, the 30-day risk of all stroke was higher for CAS ( $4.1 \%$ vs. $2.3 \%, p=0.01)$, whereas CEA was associated with a higher 30 -day risk of MI $(2.3 \% v$ s. $1.1 \%, p=0.03)$. The rate of ipsilateral stroke over a mean follow-up of 4-years was similar between groups. CAS appeared safer than CEA for patients $\leq 69$-years of age while CEA yielded better outcomes in those $>70$-years of age (Figure 3).

The CREST 10-year follow-up demonstrated that patients with periprocedural stroke were at increased risk of death compared with those without stroke (adjusted hazard ratio $[\mathrm{HR}]=1.74 ; 95 \% \mathrm{CI}, 1.21-2.50 ; p<0.003) .{ }^{27,28}$ This increased risk was driven by increased early ( $\leq 90$-days) mortality (adjusted HR=14.41; 95\% CI, 5.33-38.94; $p<0.0001)$, with no significant increase in late ( $>90$-days and 10-years) mortality (adjusted HR=1.40; 95\% CI, $0.93-2.10 ; p=0.11)$. Patients with a periprocedural MI were at 3.61 times the risk of death compared with those without MI (adjusted $\mathrm{HR}=3.61 ; 95 \% \mathrm{CI}, 2.28-5.73 ; p<0.0001)$, with an increased hazard both early (adjusted HR=8.20; 95\% CI, 1.86-36.2; $p=0.006$ ) and late (adjusted $\mathrm{HR}=3.40 ; 95 \% \mathrm{CI}, 2.09-5.53 ; p<0.0001$ ). This 
points out the importance or including periprocedural MI in the combined outcome endpoint for carotid revascularization trials.

CREST differed from the previous trials in three significant ways. Most importantly, the European randomized controlled trials (RCT) allowed inexperienced CAS operators to enroll patients. All allowed CAS operators, but not CEA operators, to be "tutored" while enrolling patients. CAS operators in the European trials were not very experienced (EVA-3S required that operators perform at least 5 CAS procedures, ICSS required 10 CAS procedures, and SPACE had no minimum number of carotid stents required). CREST requirements were more stringent. CREST required low volume CAS operators to "qualify" to enroll patients in the trial with "lead-in" patients. This step was unique and critically important when attempting to reasonably compare the newer and evolving CAS procedure with a mature, stable operation like CEA. There were 1,565 lead-in patients in CREST which is more CAS patients than were enrolled in any of the European trials.

The results obtained by relatively in experienced CAS operators participating in the lead-in phase of CREST emphasizes the importance of experience and further confirms the flaws in the European trials. Vascular surgeons, the most inexperienced specialty, had a significantly worse outcomes than did Cardiologists or Radiologists (Figure 4). ${ }^{29}$ However, that difference went away after the surgeons qualified for the trial with lead-in patients. The fact that so many (15\% to $20 \%$ ) peri-procedural neurologic events involve the non-culprit carotid circulation is evidence of the importance of catheter skills in navigating the aortic arch to reach the carotid arteries. The importance of an experienced procedure team and CAS operators cannot be overstated. Second, CREST mandated the use of EPDs whereas the other trials did not. Lastly, just over $50 \%$ of the patients in CREST were symptomatic whereas the European trials enrolled only symptomatic patients.

Figure 4. CREST Specialty Lead-In Results

\section{CREST Lead-In Specialty Outcomes} ADVERSE OUTCOMES

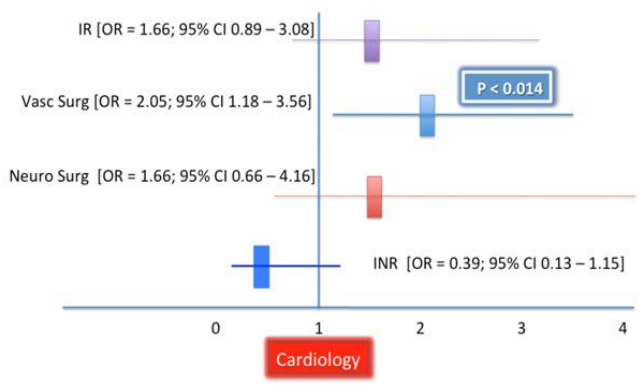

$\mathrm{IR}=$ interventional radiology, INR = interventional neuroradiology

CAS is indicated as an alternative to CEA for symptomatic ASR patients at average or low risk of complications associated with endovascular intervention when the diameter of the lumen of the internal carotid artery is reduced by more than $70 \%$ as documented by noninvasive imaging or more than $50 \%$ as documented by catheter angiography and the anticipated rate of periprocedural stroke or mortality is less than $6 \% .{ }^{20}$ It is also reasonable to choose CAS over CEA when revascularization is indicated in patients with neck anatomy unfavorable for arterial surgery.

\section{CAS in Asymptomatic Patients}

In CREST, for the 1,181 asymptomatic patients, the periprocedural period rates of the primary end point did not differ significantly between the CAS group and the CEA group (3.5\% vs. 3.6\%; hazard ratio, 1.02 ; $95 \% \mathrm{CI}, 0.55$ to $1.86, p=0.96)$ and at 4 -year follow-up there was no difference between the CAS and CEA groups $(5.6 \%$ to $4.9 \%$; hazard ratio, $1.17 ; 95 \% \mathrm{CI}, 0.69$ to $1.98, p=0.56){ }^{25}$

The asymptomatic carotid trial (ACT-1) randomized 1,453 asymptomatic ASR carotid stenosis patients to CEA or CAS. ${ }^{30}$ CAS was non-inferior to CEA with regard to death, stroke, or $\mathrm{MI}$ within 30 -days after the procedure or ipsilateral stroke within 1-year (3.8\% vs. 3.4\%, $p=0.01$ for non-inferiority). There was no difference for CAS $v$ s CEA for rates of stroke or death within 30 -days $(2.9 \%$ and $1.7 \%, p=0.33)$. Freedom from ipsilateral stroke from 30 -days to 5 -years was $97.8 \%$ in the CAS group and $97.3 \%$ in the CEA group $(p=0.51)$.

CAS in asymptomatic patients may be considered in highly selected patients with asymptomatic carotid stenosis (minimum $60 \%$ by angiography, $70 \%$ by validated Doppler ultrasound), but its effectiveness compared with medical therapy alone in this situation is not well established.

\section{SUMMARY}

In 2019, CAS has become one of the most studied medical procedures of all time. In HSR patients there is randomized trial data $^{31-47}$ favoring CAS over CEA in patients suitable for stenting.

In ASR patients, the largest randomized clinical trial $(\mathrm{CREST})^{25}$ confirms the equipoise for CAS and CEA, when these procedures are performed by experienced operators with experienced teams supporting them. In recognition of this extensive evidence-base, there is a multi-societal expert consensus document $^{48}$ and guidelines ${ }^{20,49}$ that recommend that CAS be considered a reasonable alternative to CEA.

A patient-centered approach is reasonable in candidates for carotid revascularization. The patient and their physician should discuss the available treatment options, including revascularization (either CAS or CEA) with their physician. There remains uncertainty regarding the value proposition for revascularization (either CEA or CAS) in asymptomatic patients as a strategy to prevent stroke. ${ }^{50}$ Investigation continues into characterizing high risk carotid plaque subsets, but until that data is available, physicians and patients should continue to strive to achieve the best outcomes with the information that is currently available. The other consideration in asymptomatic patients is that there is a cumulative benefit to revascularization that is dependent on life expectancy. However, 
the magnitude of the benefit of revascularization, over the longer term in the setting of multifactorial medical therapy, including statins, is not known.

No one can know exactly what the future holds for carotid stenting, but there are several reasonably safe bets. The first is that less invasive CAS will eventually replace the more invasive CEA. This change will be largely driven by the acceptance of CAS by younger, endovascularly trained vascular surgeons, who will replace the senior surgeons, who have effectively protected their surgical turf. The second is that far fewer asymptomatic patients will undergo any form of revascularization as multimodality medical therapy continues to improve. Clinical expansion of the volume of CAS cases will drive further technical enhancements and procedural evolution that will make CAS safer than CEA for stroke, death and MI and make cranial nerve injuries, a vestige of the past.

The uncertainty regarding the current best strategy for managing patients with asymptomatic carotid artery disease will be answered in the he CREST-2 trial that is currently enrolling patients and features 2 parallel arms (Figure 1): one arm compares CEA with best medical management versus best medical management alone and the other arm compares CAS and best medical management versus best medical management alone. CREST-2 does not compare CEA to CAS, but recognizes the equipoise for these two revascularization strategies in asymptomatic patients.

The stroke lowering benefit of modern pharmacotherapy has been firmly established. It has been estimated that the combined effects of antiplatelet therapy, lipid lowering, and blood pressure control could reduce the risk of recurrent stroke by as much as $80 \% .^{51}$ Secondary analyses from trials of lipid lowering therapy in patients with stroke suggest that control of blood pressure $(<120 / 80 \mathrm{~mm} \mathrm{Hg})$, low-density lipoproteins (LDL) level ( $<70 \mathrm{mg} / \mathrm{dL})$, triglycerides level $(<150 \mathrm{mg} / \mathrm{dL})$, and high-density lipoproteins (HDL) level $(>50 \mathrm{mg} / \mathrm{dL})$ can lead to a significant reduction in the risk of recurrent stroke can reduce the hazard ratio (HR) to 0.35 .

Reimbursement constraints continue to be a serious barrier to the clinical dissemination of $\mathrm{CAS}^{52}$ food and drug administration (FDA) has approved multiple CAS as "safe and effective" but centers for medicare and medicaid services (CMS) has decided that CAS is not "reasonable or necessary". CMS however reimburses for CEA without restraint or conditions.

\section{CONCLUSION}

Carotid artery stenting is a well studied therapeutic strategy for carotid revascularization, it must be performed by experienced operators using embolic protetction in orther to provide results similar to those reported in the clinical trials. The clinical benefit is clear in symptomatic patients. On the other hand, the current CREST-2 trial is evaluating its performance compared with current maximal medical therapy for patients with asymptomatic disease.

\section{CONFLICT OF INTEREST}

The authors declare that they have no conflicts of interest.

\section{REFERENCES}

1. Benjamin EJ, Virani SS, Callaway CW, et al. Heart disease and stroke statistics-2018 update: A report from the American Heart Association. Circulation. 2018; 137: e67-e492. doi: 10.1161/ CIR.0000000000000558

2. Amarenco P, Steering Committee Investigators of the to. Risk of stroke after transient Ischemic attack or minor stroke. $N$ Engl J Med. 2016; 375: 387. doi: 10.1056/NEJMc1606657

3. Markus HS, King A, Shipley M, et al. Asymptomatic embolisation for prediction of stroke in the Asymptomatic Carotid Emboli Study (ACES): A prospective observational study. Lancet Neurol. 2010; 9: 663-671. doi: 10.1016/S1474-4422(10)70120-4

4. Jalbert JJ, Nguyen LL, Gerhard-Herman MD, et al. Comparative effectiveness of carotid artery stenting versus carotid endarterectomy among medicare beneficiaries. Circ Cardiovasc Qual Outcomes. 2016; 9: 275-285. doi: 10.1161/CIRCOUTCOMES.115.002336

5. Constantinou J, Jayia P, Hamilton G. Best evidence for medical therapy for carotid artery stenosis. J Vasc Surg. 2013; 58: 11291139. doi: $10.1016 /$ j.jvs.2013.06.085

6. Amarenco P, Goldstein LB, Sillesen H, et al. Coronary heart disease risk in patients with stroke or transient ischemic attack and no known coronary heart disease: findings from the stroke prevention by aggressive reduction in cholesterol levels (SPARCL) trial. Stroke. 2010; 41: 426-430. doi: 10.1161/STROKEAHA.109.564781

7. Everett BM, Glynn RJ, MacFadyen JG, et al. Rosuvastatin in the prevention of stroke among men and women with elevated levels of C-reactive protein: Justification for the use of statins in prevention: An intervention trial evaluating rosuvastatin (JUPITER). Circulation. 2010; 121: 143-150. doi: 10.1161/ CIRCULATIONAHA.109.874834

8. Meschia JF, Bushnell C, Boden-Albala B, et al. Guidelines for the primary prevention of stroke: A statement for healthcare professionals from the American Heart Association/American Stroke Association. Stroke. 2014; 45: 3754-3832. doi: 10.1161/ STR.0000000000000046

9. Baigent C, Blackwell L, Collins R, et al. Antithrombotic trialists' (ATT) collaboration. aspirin in the primary and secondary prevention of vascular disease: Collaborative meta-analysis of individual participant data from randomized trials. Lancet. 2009; 373: 1849-1860. doi: 10.1016/S0140-6736(09)60503-1

10. Committee CS. A randomised, binded, trial of clopidogrel versus aspirin in patients at risk of ischaemic events (CAPRIE). Lancet. 1996; 348: 1329-1339. doi: 10.1016/s0140-6736(96)09457-3 
11. Diener HC, Bogousslavsky J, Brass LM, et al. Aspirin and clopidogrel compared with clopidogrel alone after recent ischaemic stroke or transient ischaemic attack in high-risk patients (MATCH): randomised, double-blind, placebo-controlled trial. Lancet. 2004; 364: 331-337. doi: 10.1016/S0140-6736(04)16721-4

12. Bhatt DL, Fox KA, Hacke W, et al. Clopidogrel and aspirin versus aspirin alone for the prevention of atherothrombotic events. N Engl J Med. 2006; 354: 1706-1717. doi: 10.1056/NEJMoa060989

13. Hobson RW, 2nd, Weiss DG, Fields WS, et al. Efficacy of carotid endarterectomy for asymptomatic carotid stenosis. The Veterans Affairs Cooperative Study Group. N Engl J Med. 1993; 328: 221-227. doi: 10.1056/NEJM199301283280401

14. Executive Committee for the Asymptomatic Carotid Atherosclerosis Study (ACAS). Endarterectomy for asymptomatic carotid artery stenosis. JAMA. 1995; 273: 1421-1428. doi: $10.1001 /$ jama.1995.03520420037035

15. Halliday A, Mansfield A, Marro J, et al. Prevention of disabling and fatal strokes by successful carotid endarterectomy in patients without recent neurological symptoms: Randomised controlled trial. Lancet. 2004; 363: 1491-1502. doi: 10.1016/S01406736(04)16146-1

16. Yang C, Bogiatzi C, Spence JD. Risk of stroke at the time of carotid occlusion. JAMA Neurol. 2015; 72: 1261-1267. doi: 10.1001/jamaneurol.2015.1843

17. Barnett HJ, Taylor DW, Eliasziw M, et al. Benefit of carotid endarterectomy in patients with symptomatic moderate or severe stenosis. North American symptomatic carotid endarterectomy trial collaborators. N Engl J Med. 1998; 339: 1415-1425. doi: 10.1056/NEJM199811123392002

18. Inzitari D, Eliasziw M, Sharpe BL, Fox AJ, Barnett HJ. Risk factors and outcome of patients with carotid artery stenosis presenting with lacunar stroke. North American Symptomatic Carotid Endarterectomy Trial Group. Neurology. 2000; 54: 660-666. doi: 10.1212/wnl.54.3.660

19. European Carotid Surgery Trialists' Collaborative Group. Randomised trial of endarterectomy for recently symptomatic carotid stenosis: final results of the MRC European Carotid Surgery Trial (ECST). Lancet. 1998; 351: 1379-1387.

20. Brott TG, Halperin JL, Abbara S, et al. 2011 ASA/ACCF/ AHA/AANN/AANS/ACR/ASNR/CNS/SAIP/SCAI/SIR/ SNIS/SVM/SVS guideline on the management of patients with extracranial carotid and vertebral artery disease: Executive summary a report of the American college of cardiology foundation/ American heart association task force on practice guidelines, and the American stroke association, American association of neuroscience nurses, American association of neurological surgeons, American college of radiology, American society of neuroradiology, congress of neurological surgeons, society of atherosclerosis imaging and prevention, society for cardiovascular angiography and interventions, society of interventional radiology, society of neurointerventional surgery, society for vascular medicine, and society for vascular surgery developed in collaboration with the American academy of neurology and society of cardiovascular computed tomography. J Am Coll Cardiol. 2011; 57: 1002-1044. doi: 10.1016/j.jacc.2010.11.005

21. Yadav JS, Wholey MH, Kuntz RE, et al. Protected carotidartery stenting versus endarterectomy in high-risk patients. $N$ Engl J Med. 2004; 351: 1493-1501. doi: 10.1056/NEJMoa040127

22. Ringleb PA, Allenberg J, Bruckmann H, et al. 30 day results from the SPACE trial of stent-protected angioplasty versus carotid endarterectomy in symptomatic patients: A randomised noninferiority trial. Lancet. 2006; 368: 1239-1247. doi: 10.1016/S01406736(06)69122-8

23. Mas JL, Chatellier G, Beyssen B, et al. Endarterectomy versus stenting in patients with symptomatic severe carotid stenosis. $N$ Engl J Med. 2006; 355: 1660-1671. doi: 10.1056/NEJMoa061752

24. International Carotid Stenting Study Investigators, Ederle J, Dobson J, et al. Carotid artery stenting compared with endarterectomy in patients with symptomatic carotid stenosis (International Carotid Stenting Study): An interim analysis of a randomised controlled trial. Lancet. 2010; 375: 985-997. doi: 10.1016/S0140-6736(10)60239-5

25. Brott TG, Hobson RW, 2nd, Howard G et al. Stenting versus endarterectomy for treatment of carotid-artery stenosis. N Engl J Med. 2010; 363: 11-23. doi: 10.1056/NEJMoa0912321

26. Bonati LH, Dobson J, Featherstone RL, et al. Long-term outcomes after stenting versus endarterectomy for treatment of symptomatic carotid stenosis: The International Carotid Stenting Study (ICSS) randomised trial. Lancet. 2015; 385: 529-538. doi: 10.1016/S0140-6736(14)61184-3

27. Jones MR, Howard G, Roubin GS, et al. Periprocedural stroke and myocardial infarction as risks for long-term mortality in CREST. Circ Cardiovasc Qual Outcomes. 2018; 11: e004663. doi: 10.1161/CIRCOUTCOMES.117.004663

28. Arya S, Girotra S. Long-term mortality in carotid revascularization patients. Circ Cardiovasc Qual Outcomes. 2018; 11: e004875. doi: 10.1161/CIRCOUTCOMES.118.004875

29. Hopkins LN, Roubin GS, Chakhtoura EY, et al. The carotid revascularization endarterectomy versus stenting trial: Credentialing of interventionalists and final results of lead-in phase. J Stroke Cerebrovasc Dis. 2010; 19: 153-162. doi: 10.1016/j. jstrokecerebrovasdis.2010.01.001

30. Rosenfield K, Matsumura JS, Chaturvedi S, et al. Randomized trial of stent versus surgery for asymptomatic carotid stenosis. $N$ Engl J Med. 2016; 374: 1011-1020. doi: 10.1056/NEJMoa1515706

31. Yadav J, the Sapphire Investigators. Stenting and angioplasty 
with protection in patients at high risk for endarterectomy: The SAPPHIRE study. Circulation. 2002; 106: 2986a.

32. Gray WA, Hopkins LN, Yadav S, et al. Protected carotid stenting in high-surgical-risk patients: The ARCHeR results. J V asc Surg. 2006; 44: 258-268. doi: 10.1016/j.jvs.2006.03.044

33. Whitlow P. Security: More good data for protected carotid stenting in high-risk surgical patients. 2003.

34. Higashida RT, Popma JJ, Apruzzese P, et al. Evaluation of the medtronic exponent self-expanding carotid stent system with the medtronic guardwire temporary occlusion and aspiration system in the treatment of carotid stenosis: Combined from the MAVErIC (Medtronic AVE Self-expanding CaRotid Stent System with distal protection in the treatment of Carotid stenosis) I and MAVErIC II trials. Stroke. 2010; 41: e102-9. doi: 10.1161/ STROKEAHA.109.564161

35. Safian RD, Jaff MR, Bresnahan JF, et al. Protected carotid stenting in high-risk patients: results of the spideRX arm of the carotid revascularization with ev3 arterial technology evolution trial. J Interv Cardiol. 2010; 23: 491-498. doi: 10.1111/j.15408183.2010.00578.x

36. Coppi G, Moratto R, Silingardi R, et al. PRIAMUS--proximal flow blockage cerebral protectIon during carotid stenting: Results from a multicenter Italian registry. J Cardiovasc Surg (Torino). 2005; 46: 219-227.

37. White CJ, for the Beach Investigators. BEACH Trial: 30 day outcomes of carotid wallstent and filterwire EX/EZ distal protectioin system placement for treatment of high surgical risk patients. J Am Coll Cardiol. 2005; 45: 28 A.

38. Safian RD, Bacharach JM, Ansel GM, et al. Carotid stenting with a new system for distal embolic protection and stenting in high-risk patients: The carotid revascularization with ev3 arterial technology evolution (CREATE) feasibility trial. Catheter Cardiovasc Interv. 2004; 63: 1-6. doi: 10.1002/ccd.20155

39. Gray WA, Yadav JS, Verta P, et al. The CAPTURE registry: Results of carotid stenting with embolic protection in the post approval setting. Catheter Cardiovasc Interv. 2007; 69: 341-348. doi: 10.1002/ccd.21050

40. Katzen BT, Criado FJ, Ramee SR, et al. Carotid artery stenting with emboli protection surveillance study: Thirty-day results of the CASES-PMS study. Catheter Cardiovasc Interv. 2007; 70: 316-23. doi: $10.1002 / \operatorname{ccd} .21222$

41. Hopkins LN, Myla S, Grube E, et al. Carotid artery revascularization in high surgical risk patients with the nexstent and the Filterwire EX/EZ: 1-year results in the CABERNET trial. Catheter Cardiovasc Interv. 2008; 71: 950-960. doi: 10.1002/ccd.21564
42. Matsumura JS, Gray W, Chaturvedi S, et al. CAPTURE 2 riskadjusted stroke outcome benchmarks for carotid artery stenting with distal embolic protection. J V asc Surg. 2010; 52: 576-583, 583 e1-583 e2. doi: 10.1016/j.jvs.2010.03.064

43. Gray WA, Chaturvedi S, Verta P. Thirty-day outcomes for carotid artery stenting in 6320 patients from 2 prospective, multicenter, high-surgical-risk registries. Circ Cardiovasc Interv. 2009; 2: 159-166. doi: 10.1161/CIRCINTERVENTIONS.108.823013

44. Ansel GM, Hopkins LN, Jaff MR, et al. Safety and effectiveness of the INVATEC MO.MA proximal cerebral protection device during carotid artery stenting: Results from the ARMOUR pivotal trial. Catheter Cardiovasc Interv. 2010; 76: 1-8. doi: 10.1002/ccd.22439

45. Myla S, Bacharach JM, Ansel GM, et al. Carotid artery stenting in high surgical risk patients using the FiberNet embolic protection system: The EPIC trial results. Catheter Cardiovasc Interv. 2010; 75: 817-822. doi: 10.1002/ccd.22386

46. Clair DG, Hopkins LN, Mehta M, et al. Neuroprotection during carotid artery stenting using the GORE flow reversal system: 30day outcomes in the EMPiRE Clinical Study. Catheter Cardiovasc Interv. 2011; 77: 420-429. doi: 10.1002/ccd.22789

47. Matsumura JS, Gray W, Chaturvedi S, et al. Results of carotid artery stenting with distal embolic protection with improved systems: Protected Carotid Artery Stenting in Patients at High Risk for Carotid Endarterectomy (PROTECT) trial. J Vasc Surg. 2012; 55: 968-976 e5. doi: 10.1016/j.jvs.2011.10.120

48. Bates ER, Babb JD, Casey DE, et al. ACCF/SCAI/SVMB/SIR/ ASITN 2007 clinical expert consensus document on carotid stenting. Vasc Med. 2007; 12: 35-83. doi: 10.1177/1358863X06076103

49. Furie KL, Kasner SE, Adams RJ, et al. Guidelines for the prevention of stroke in patients with stroke or transient ischemic attack: A guideline for healthcare professionals from the American Heart Association/American Stroke Association. Stroke. 2011; 42: 227-276. doi: 10.1161/STR.0b013e3181f7d043

50. Beckman JA. Management of asymptomatic internal carotid artery stenosis. JAMA. 2013; 310: 1612-1618. doi: 10.1001/ jama.2013.280039

51. Hackam DG, Spence JD. Combining multiple approaches for the secondary prevention of vascular events after stroke: A quantitative modeling study. Stroke. 2007; 38: 1881-1885. doi: 10.1161/STROKEAHA.106.475525

52. White CJ, Jaff MR. Catch-22: Carotid stenting is safe and effective (Food and Drug Administration) but is it reasonable and necessary (Centers for Medicare and Medicaid Services)? JACC Cardiovasc Interv. 2012; 5: 694-696. doi: 10.1016/j.jcin.2012.05.001 